\title{
Effects of Curcumin on Vascular Endothelial Growth Factor Expression on Rattus norvegicus Cervical Cancer Xenograft Model
}

\author{
Laili Muninggar ${ }^{1}$, Widjiati $^{2}$, Indra Yuliati ${ }^{1 *}$, Brahmana Askandar ${ }^{1}$, Poedjo Hartono \\ ${ }^{1}$ Department of Obstetric and Gynecology, Dr.Soetomo Hospital/Airlangga University, Surabaya \\ ${ }^{2}$ Department of Embryology, Faculty of Veterinary Medicine, Airlangga University, Surabaya
}

\section{ARTICLE INFO}

\section{Article history:}

Received : 17 September 2018

Reviewed: 31 October 2018

Accepted : 27 December 2018

Keywords: Cervical cancer, Curcumin, VEGF, Xenograft

\begin{abstract}
A BSTRACT
Objective: To analyze the effect of curcumin in VEGF expression on Rattus norvegicus cervical cancer cell xenograft model.

Methods: An experimental study with randomized post test only control group design. The subjects were Rattus norvegicus (Sprague Dawley), inoculated with He-la cervical cancer cells from American Type Culture Collection (ATCC) processed in stem cell laboratory Institute of Tropical Disease (ITD) Airlangga University. $5 \times 10^{6}$ of He-La cells were injected subcutaneously in dorsal flank area of Rattus norvegicus. After 30 days of observation we performed histopathological examination of xenograft tissue and randomized into 2 groups which were given curcumin orally $1000 \mathrm{mg} / \mathrm{kg}$ (curcumin group) vs. no therapy (control group). After another 30 days the xenograft tissue was dissected and underwent immunochemistry examination for VEGF expression.
\end{abstract}

Results: 32 samples of Rattus norvegicus were divided into 2 groups, In curcumin group the VEGF median expression was 2,2 $(0,3-7,6)$ and in control group the VEGF median expression was $6,6(1,2-12)$. There was a statistically significant difference with $p$ value $=0,009$ with Mann Whitney test $(p<0,05)$.

Conclusion: VEGF expression in Rattus norvegicus xenograft model of cervical cancer was suppressed by giving Curcumin $1000 \mathrm{mg} / \mathrm{kgBB}$ orally.

\author{
*Corresponding author: \\ Indra Yuliati, Department of \\ Obstetric and Gynecology, Dr. \\ Soetomo Hospital, Airlangga \\ University, Surabaya. \\ E-mail: Indrayuliatialif@yahoo.com
}

Curcumin, is one of the natural ingredients from turmeric extract (Curcuma longa), is a type of tubers that are easily found, especially in Asian countries. Several previous studies had proven the biological and pharmacological effects of curcumin, including antiinflammatory, anti-oxidant, anti-artritic, anti-cancer, hepato-protective, anti-depressant, cardio-protective, anti-diabetic, immunomodulator, anti-Alzheimer's and analgesic. The benefits of curcumin as an anti-cancer have been widely proven, both in-vitro and in-vivo studies, including breast cancer, pancreatic cancer, cervical cancer and colon cancer. Curcumin works through various cellular pathways that suppress cancer growth (4). But the effect of curcumin on cervical cancer through the angiogenesis pathway has not been widely proven in-vivo.

\section{METHODS}

This is an experimental analytic study with a randomized post-test only control group design. The subjects of the study were Rattus norvegicus Sprague 
Dawley strain that had been inoculated by He-La cervical cancer cells (American Type Culture Collection (ATCC) from the stem cell laboratory of the Institute of Tropical Disease (ITD), Airlangga University.

A total of $5 \times 106$ he-La cells were injected subcutaneously in the dorsal flank area. After 30 days observation, histopathology examination was carried out to identify xenograft tissue. Randomization was done and we divided the subjects into two groups: the treatment group which received oral curcumin $1000 \mathrm{mg}$ / kg body weight, using curcumin for synthesis from Merck-Schuchardt, Germany with ingredients of curcumin $90 \%$, and control group which did not get any therapy.

After 30 days of curcumin treatment, xenograft tissue was dissected, and underwent immunohistochemical examination of VEGF expression. VEGF expression from each sample was assessed semiquantitatively according to the modified Remmele method, which is the multiplication result from immunoreactive cells with color intensity score on immunoreactive cells. Data for each sample was the average IRS value observed in 10 different field of view at $100 x$ and $400 x$ magnification. The calcutation of VEGF data was analyzed with Mann-Whitney test.

This research was carried out in animal and pathology laboratory, Faculty of Veterinary Medicine, Airlangga University, from January to March 2018 after obtaining ethical clearance from the Commission for Research Ethics, Faculty of Veterinary Medicine, Alrlangga University No. 2.KE.049.03.2018

\section{RESULTS}

Rattus norvegicus were injected subcutaneously with $5 \times 106$ cervical cancer He-La cells in the dorsal flank area, with cyclosporine injected as immunosuppressant. After a 30-day observation, xenograft tissue was identified with histopathology examination. Randomization was carried out, 32 samples were divided into 2 groups, 16 samples in each group. In the treatment group curcumin $1000 \mathrm{mg} / \mathrm{kg} /$ day was given orally, while in the control group no curcumin was given.

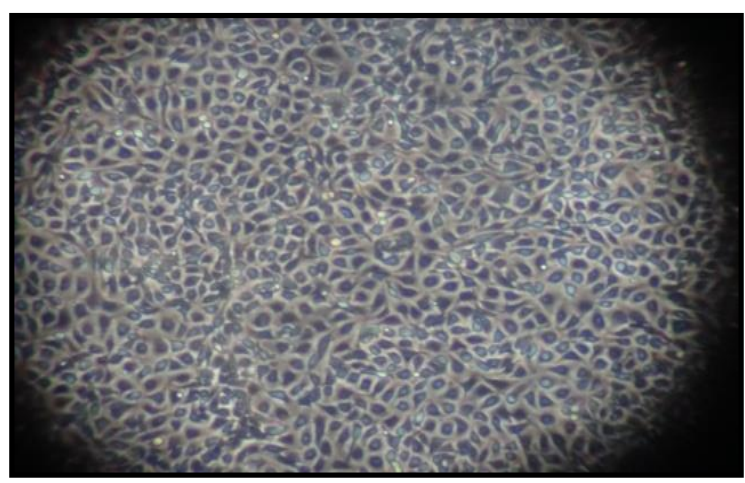

Figure 1. He-La cells from ATCC (American Type Culture Collection)
After 30 days of treatment, xenograft tissue dissection was performed and immunohistochemical examination was performed to quantify VEGF expression.

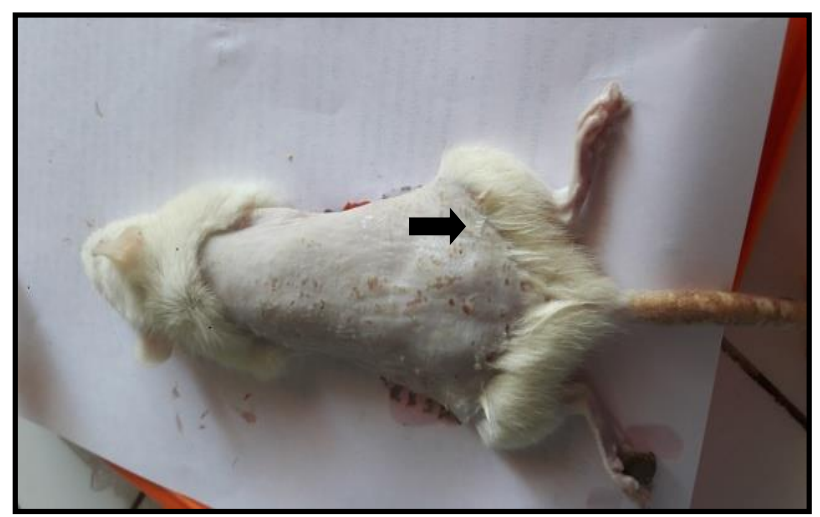

Figure 2. Xenograft tissue in the dorsal flank area of Rattus norvegicus.

From the immunohistochemical examination, we obtained an overview of VEGF expression in the control and treatment groups (Figure 3 and Figure 4), with data analysis (Table 1).

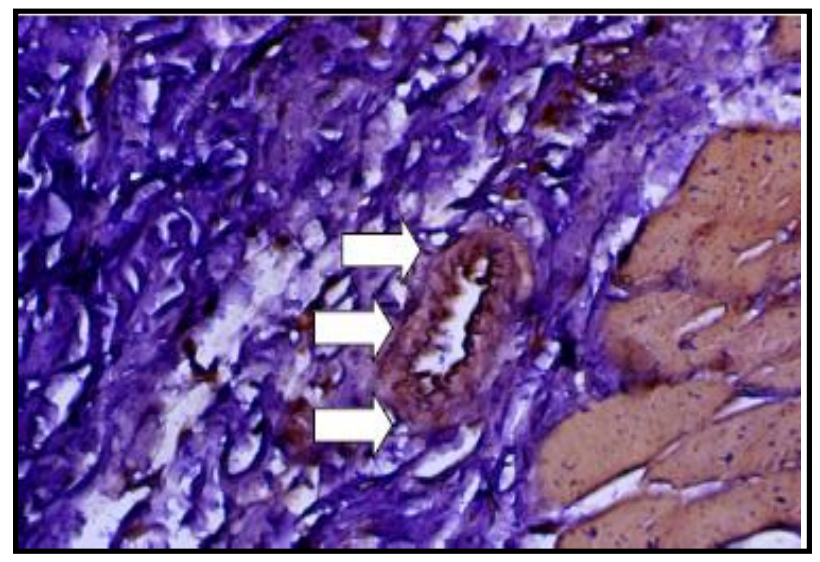

Figure 3. Overview of VEGF expression in the control group showing chromogen brown color in the vascular endothelium.

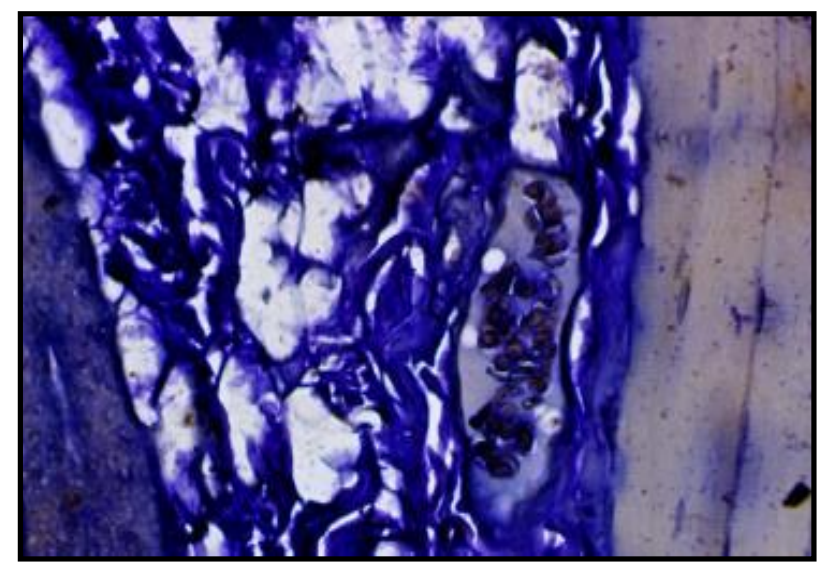

Figure 4. Overview of VEGF expression in the curcumin group showed no brown chromogen in the vascular endothelium 
Table 1. Comparison of VEGF expression in the control and curcumin group (Total sample $=32$ )

\begin{tabular}{ccccc}
\hline \multirow{2}{*}{ Group } & \multicolumn{4}{c}{ VEGF Expression } \\
\cline { 2 - 5 } & Median & Min. & Max. & \\
\hline Control $(\mathrm{N}=16)$ & 6,60 & 1,2 & 12 & $\mathrm{P}=0,009^{*}$ \\
Curcumin $(\mathrm{N}=16)$ & 2,20 & 0,3 & 7,6 & \\
\hline
\end{tabular}

* Mann Whitney test

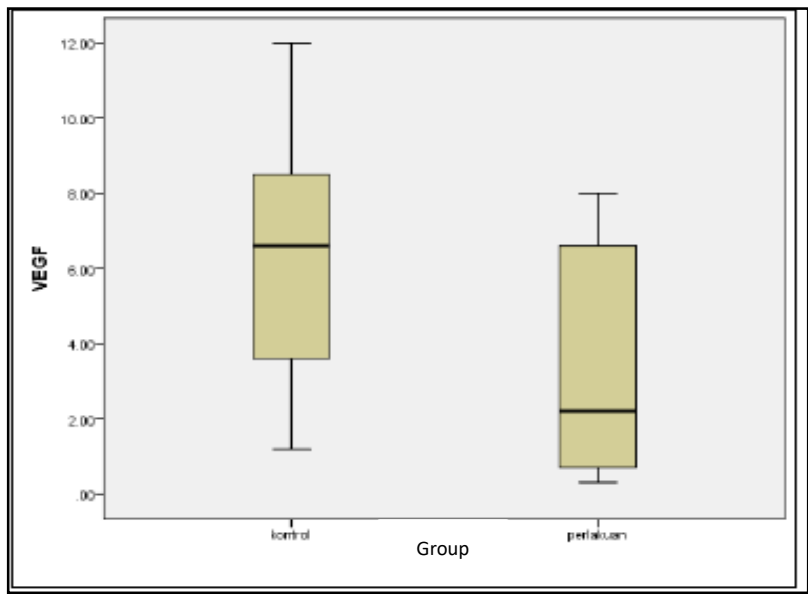

Figure 5. Box plot median VEGF expression in the control and curcumin groups.

\section{DISCUSSION}

Management option for early stage cervical cancer is surgery, with a 5-year survival rate of 85 to $95 \%$, whereas in the advanced stages, chemoradiation is a therapeutic option. Most cervical cancer patients came already in advanced stage due to the lack of screening programs. In advanced stage of cervical cancer, the main therapeutic options are radiation and chemotherapy. However, $30-40 \%$ of patients do not respond well to radiotherapy. The limitation of radiation facilities also causes the lengthening of the therapy duration which has an effect on increasing the recurrence rate and decreasing survival rate. Chemotherapy also does not provide maximum benefits due to side effects, toxicity, and high resistance (5).

The development of medical science in finding cervical cancer therapy then leads to development of novel anti-angiogenic agents, such as bevacizumab, sunitinib, pazopanib and imatinib. In the GOG 240 study, bevacizumab significantly improves overall survival when combined with chemotherapy in patients with recurrent or persistent and metastatic cervical cancer.

Inhibition of VEGF by bevacizumab results in disruption of the angiogenesis process wherein the cervical cancer, the process of angiogenesis occurs very active. The angiogenesis is the target of further anticancer research, because angiogenesis is a very important factor in tumor growth, which when the tumor has grown to a certain size, the tumor requires a new blood vessel (6).

Angiogenesis is the process by which new blood vessels are formed from vascular beds that already existed. Angiogenesis is an important process for tumor growth from localized small tumors to large tumors that have metastatic ability. When tumor growth reaches a size of $+1-2 \mathrm{~mm}$ in diameter or with a number of cells around 106 cells, the tumor requires remodeling and vascular growth, in addition to providing sufficient blood flow and also increases the chance of the tumor metastasis hematogenously (7).

VEGF induces angiogenesis through direct effects on endothelial cells. In vitro studies showed microvascular growth of endothelial cells on the surface of 3 dimensional collagen gels and VEGF was shown to induce cells to invade the underlying matrix and form a capillary-like tube structure. VEGF also produces a nonmitogenic response by vascular endothelial cells. Endothelial cells in newly formed blood vessels undergo apoptosis with no signal to survive. By inducing antiapoptotic signals, VEGF is important for maintaining immature vascular viability (8).

There is in-vivo evidence that VEGF can rapidly increase vascular permeability which results in leakage of plasma proteins and extravascular matrix, which further improves the environment that suitable for endothelial cell growth. In addition, increased vascular permeability will also increase interstitial pressure. Finally VEGF will induce chemotaxis, and expression of plasminogen activator and collagen in endothelial cells (9).

VEGF is a key mediator of angiogenesis because it facilitates growth and remodeling processes of blood vessel, and provides mitogenic stimulation and survival for endothelial cells. VEGF also affects the immune system through several pathways. Experimental studies had shown that VEGF directly affects T-cells from early progenitor cells in the hematopoeiesis process and produces dendritic cells that are not functioning effectively (10). In addition, VEGF has been shown to have a mobilizing effect on endothelial precursor cells circulating in the vascular and hematopoietic stem cells, through mediation of monocyte migration (11).

In this study, xenograft was performed using He-La cervical cancer cells. Several types of cervical cancer cell cultures that are widely used in research include He-La cells, Ca-Ski cells, and $\mathrm{Si}-\mathrm{Ha}$ cells. He-la cell culture is the first cell culture, permanent and most widely used. This culture comes from cervical cancer cells taken on February 8, 1951 in patients with Henrietta Lacks, who later died of cancer. The xenograft model using He-la cells was first introduced in 1980 by Hisashi (7).

Curcumin, an active phytochemical extraction ingredient from turmeric (Curcuma longa sp.), an Indian native spice plant which was first discovered in 1815 by Vo-gel and Pelletier. The chemical structure of curcumin 
as diferuloylmethane was discovered by Milobedzka et al (1910). Since then, this polyphenol has been widely studied for its biochemical effects for medicinal purposes.

Turmeric is widely processed by biotechnology companies, making it commercially available. Turmeric is generally safe for consumption, and has been recognized as Generally Recognized as Safe (GRAS) by the FDA. Chemical analysis of turmeric contains protein $(6.3 \%)$, fat $(5.1 \%)$, minerals $(3.5 \%)$ carbohydrates (69.4\%) and moisturizers (13.1\%). Essential oils (5.8\%) obtained from heating turmeric contained phellandrene (1\%), sabinene $(0.6 \%)$, cineol (1\%), borneol $(0.5 \%)$, zingiberene (25\%), sesquiterpines( $53 \%)$, and curcumin (3-6\%). The chemical formula of curcumin is $\mathrm{C} 21 \mathrm{H} 2006$ with chemical structure [1,7-bis- (4'-hydroxy-3'methoxyphenyl) hepta-1,6-diena-3,5-dion]. Curcumin is insoluble at neutral and acidic $\mathrm{pH}$ but can dissolve in methanol, ethanol, dimethylsulfoxide, and acetone. Some researchers have proven the sensitivity of curcumin to light so that materials containing curcumin are recommended to be protected from light (12).

There had been many studies stated that curcumin is effective and safe. In experimental animals, oral administration of curcumin can reach serum and plasma. In humans, $3.6 \mathrm{~g}$ of oral curcumin were found to produce plasma curcumin $11.1 \mathrm{nmol} / \mathrm{L}$ after 1 hour consumption. To improve the low bioavailability of this curcumin several strategies were studied, among others, by changing the route of administration, medium used, conjugation and modification of curcumin such as nanocurcumin, liposome encapsulated curcumin, silica coated curcumin, and so on. The administration of curcumin with piperine is also a way to inhibit the rapid metabolism of curcumin (13).

In clinical trials on colon cancer patients, administration of curcumin orally up to $8 \mathrm{~g} / \mathrm{kg} /$ day was found to be safe and did not cause toxicity (8), while experiments in mice with $1000-1500 \mathrm{mg} / \mathrm{kg}$ body weight curcumin for 30 days had suppressed effect in VEGF, and inhibits the process of angiogenesis (14).

Anti-cancer activity of curcumin was first proven both in vitro and in vivo by Kuttan et al in 1980 (15). In 1995, it was found that curcumin increased antiinflammatory activity by suppressing the proinflammatory transcription factor nuclear factor (NF) -KB anti-potency curcumin cancer works by modulation of several cell signaling pathways including transcription factors, inflammatory cytokines, enzymes, kinases, growth factors, receptors, and various other proteins. Furthermore, curcumin also effectively regulates tumor cell growth through modulation of many cell signaling pathways and potentiates the effects of chemotherapy and radiation agents. Curcumin can interact with most targets stimulated by FDA-approved drugs for cancer therapy (16).

The potential benefits of curcumin as an anti-cancer agent have been investigated in various studies both pre-clinical and clinical studies. In-vitro research and pre-clinical experiments show that the anti-carcinogenic activity of curcumin to be very promising, with its activity as an anti-cancer that can affect various pathways. In colon cancer, a combination therapy of oxaliplatin, 5-FU and leucovorin given with curcumin at a dose of 5 grams per day provides a good anticancer effect without any side effects at 5 months after therapy (17). In clinical trials in pancreatic cancer patients with poor prognosis, administration of curcumin significantly increased tumor regression (73\%) along with an increase of $3-25 \%$ cytokines in the blood (12). Curcumin also has anti-leukemic effects by decreasing Nitric oxide (NO) synthesis in patients with chronic myeloid leukemia (18).

The role of curcumin as an anti-HPV and anti-cervical cancer had been widely proven. The synergistic effect of curcumin with chemotherapeutic agents in-vitro showed that combination curcumin with paclitaxel increased apoptosis in cervical cells infected with HPV compared to paclitaxel alone (19). While administration of curcumin along with cisplatin was found to increase cell sensitivity to cisplatin through suppression of multidrug resistance protein (MRP) and P-glycoprotein (Pgp) by curcumin (20).

Curcumin has been shown to reduce cell viability at various levels of cervical cancer cells. The administration of curcumin in He-La cervical cell culture resulted in changes in cell morphology, namely cell shrinkage. Curcumin also limits the metastases of cervical cancer, as well as regulation of NF-kB and cyclooxygenase-2 (COX-2) (22).

The most widely used xenograft process is He-La cells in cervical cancer patients. HeLa cell culture or HeLa cell line is a continuous cell line derived from cervical cancer epithelial cells of a woman named Henrietta Lacks who died of cancer in 1951. He-La cells are quite safe and are commonly used for the benefit of cell culture. HeLa is immortal which can divide indefinitely as long as it fulfills the basic conditions for the cell to remain alive. New strains of He-La cells have been developed in various cell cultures, but all He-La cells come from the same breed. He-La cells are cervical cancer cells due to infection with Human Papillomavirus (HPV 18) so that they have different properties with normal cervical cells. He-La cells can grow aggressively in suitable culture media (23).

Various researches had been done on cervical cancer using He-La cells before. Research with He-La cells invitro showed that Curcuma longa extract caused morphological changes in cells characterized by diminishing cell size, loss of cytoplasmic processes so that cells were spherical, and lost contact with other cells which are characteristic of apoptosis in most He-La cells. The nucleus appears dark because of the increased absorption capacity of the haematoxylene substance. 
Statistical analysis showed significant differences between positive and negative control groups with stimulation groups in the number of cells undergoing morphological changes towards apoptosis. It was concluded that Curcuma longa extract was able to induce changes in He-La cell morphology in the form of cell shrinkage (21). In this study no measurement of tumor volume was carried out because the tumor tissue produced was small with unclear limits. This could be due to the type of mouse model used or the insufficient observation time. Previous research using 'athymic C57BL / 6 nude mice' mice with the same He-La cell injection of $5 \times 106$, with a 30-day observation time, found a significant tumor growth of $\pm 1 \mathrm{~cm}$, and carried out a volume measurement using the formula (length $x$ width2 $\times 0.52$ ) (8)

Animal models had been developed for research on cancer. Experimental animal models were used to find factors involved in the malignancy transformation, invasion and metastasis, and to evaluate the response to therapy. One of the most widely used models is the xenograft tumor model. In this model human-derived tumor cells were transplanted under the skin or in other organs where the tumor originated in immunocompromized mice to minimize the rejection response of human cells. The tumor will grow within 1-8 weeks, depending on the number of cells injected or the size of the transplanted tumor, and then the response to therapy can be studied in vivo. Another type of experimental animal to study cancer is the genetically engineered mouse model (GEM). The genetic profile of these mice has been changed. Furthermore, the effects of gene change are studied for a long time and the therapeutic response to these tumors can be followed in vivo. Both xenograft and GEM have been used for decades to find out the factors that influence tumor growth (24).

Arjomandnejad in 2014 also conducted a study using a xenograft model in female C57BL/ 6 mice with $5 \times 106$ He-La cells for CK, vimentin, P53, CD34 and Ki-67 examination. After a latency of about 1 week, tumors begin to form with histological features showing malignancy with hyperchromatin cells. It was concluded that the use of xenograft with He-La cells was representative for cancer research and opened up great opportunities for the development of research on novel therapies for cervical cancer (8).

In this study, the results of VEGF expression in the curcumin group were lower than the control group with mean of 2,2 in the treatment group and 6,6 in the control group. For data analysis, Mann-Whitney test was tested, found significant differences in VEGF expression in the control group and curcumin group with a significance value of $p=0.009(p<0.05)$. VEGF expression was found to have decreased in this study by giving oral curcumin at a dose of $1 \mathrm{~g} / \mathrm{kg} \mathrm{BW/} \mathrm{day} \mathrm{for} 30$ days. Another study using Ca-Ski cervical cancer cell xenograft model showed high dose of curcumin (1000 $\mathrm{mg}$ and $1500 \mathrm{mg} / \mathrm{kg} /$ day) inhibited tumor growth (36\%) and angiogenesis with decrease in VEGF, COX-2 and EGFR while administration $500 \mathrm{mg} / \mathrm{kg} \mathrm{BW/} \mathrm{day} \mathrm{had}$ not shown beneficial effect. (14). Therefore this study used curcumin $1000 \mathrm{mg} / \mathrm{kg} \mathrm{BW/} \mathrm{day} \mathrm{orally} \mathrm{for} 30$ days of administration.

In cervical cancer, there is also an excessive inflammatory process like in other cancers. NF-kB is a transcription factor that is maintained in an inactive form and resides in the cytoplasm by binding to the IkBa subunit in normal cells. With phosphorylation or degradation of IkBa, they are released and translocated to the nucleus where they cause cell division. Activation of NF-kB is known to induce anti-apoptosis and prometastatic molecules including COX-2, cyclin D1, angiogenic factors (VEGF), cell matrix proteolytic enzymes (MMP-2 and MMP-9), and antiapoptotic proteins (Bcl-2, c-IAP1, surviving, and XIAP). In addition to being influenced by the process of angiogenesis, tumor growth is also influenced by the balance between proapoptotic and anti apoptotic proteins. The limitation of this study is that we only analyzed VEGF expression, while the expression of pro-apoptotic proteins,antiapoptotic proteins, and also MVD measurement were not performed.

Curcumin is shown to inhibit the carcinogenesis by suppressing pro-angiogenic mediators such as VEGF and fibroblast growth factor (FGF). The anti-angiogenic activity of curcumin basically begins with its inhibitory effect on NF-KB transcription. Curcumin then inhibits matrix metallopreotease, plasminogen acivator and cell adhesion molecules associated with inhibition of angiogenesis. The effect of curcumin on the entire process of angiogenesis shows the potential of curcumin as an anti-angiogenic therapy.

Various mechanisms can regulate VEGF, the most important is hypoxia. Hypoxia inducible factor (HIF1) is the main mediator of the hypoxic response. VEGF expression in tumor cells is stimulated by hypoxia, oncogenes, and inactivation of tumor suppressor genes (p53) and by various cytokines such as COX-2. In this study the presence of HIF1 was not studied, but theoretically the presence of stimulated free radicals from He-La cell injection is most likely to increase HIF1. In oxygen-sufficient cells HIF1 $\alpha$ is synthesized and degraded continuously, but in hypoxia the degradation is inhibited so that HIF1 $\alpha$ accumulates and polymerizes with HIF1 $\beta$ then binds DNA and recruits co-activator, so that it can activate the transcription of the target gene. Thus HIF1, which regulates various coordinated genes, works on the process of angiogenesis.

Previous research from Shan found that curcumin inhibits the synthesis of hypoxia-induced mRNA and secretion from VEGFA in GH3 cells and the culture of pituitary adenoma cells in humans supports the suppressive effect on neovascularization of pituitary 
tumors (25). Several other cancer studies have also stated that curcumin suppresses VEGF expression in Ehrlich tumor ascites cells and NIH3T3 cells (26), in pancreatic tumors (16), and in ovarian cancer (27).

Curcumin can reduce the concentration of VEGF, IL$1 \beta$ and IL-4 in patients with colorectal cancer, lung cancer, liver cancer and also obesity. Curcumin also decreases ROS, VEGF, and PDGF in patients with Age Related Macular Degeneration Retinal Pigment Epithelium (AMD-RPEs) (4).

Inhibition of VEGF secretion is also an effective strategy to prevent the spread of breast cancer because VEGF is the most potent angiogenic factor, regulated by NF-KB. Curcumin can inhibit metastasis and the angiogenic pathway in breast cancer cells through modulation of NF-KB protein expression of signaling pathways associated with NF-KB including VEGF (28).

Curcumin suppress VEGF through the NF-kB pathway. Activation of NF-kB will induce several antiapoptotic and pro-metastatic molecules including COX-2 proinflammatory proteins, cyclin-D1 cell cycle regulator proteins, angiogenic factors (VEGF), cell matrix proteolytic enzymes (MMP-2 and MMP-9), ICAM cell adhesion molecules and antiapoptotic proteins ( $\mathrm{BCl}-2$, $\mathrm{C}$ IAP1, surviving, and XIAP). Curcumin also acts as a chemopreventive and anti-inflammatory agent by reducing HPV carcinogenesis and reducing the deregulation of various regulatory biomolecules, signaling pathways, and proinflammatory mediators, and limiting cervical cancer cell metastases (4).

Research on animals given curcumin at a dose of $1 \mathrm{~g}$ / kg BW/ day had a suppressive effect on VEGF. Previous studies have shown that curcumin in mice will rapidly metabolized through conjugation and reduction hence low bioavailability. Whereas in humans, the pharmacokinetics of curcumin is inconclusive. Clinical research in patients with pre-malignant lesions from colorectal cancer given curcumin up to $8 \mathrm{~g}$ per day for 3 months does not cause toxicity (29).

Research has shown that oral administration of curcumin in pancreatic cancer patients is well tolerated, even with low absorption, showing good biological activity. Tumor regression (73\%) was accompanied by a significant (4-35-fold) increase in the number of cytokines (IL-6, IL-8, IL-10) (30).

Another study on prostate cancer patients, which curcumin were administered at a dose of $6 \mathrm{mg} /$ day combined with Docetaxel chemotherapy, was well tolerated, no toxicity, and reduced PSA (Prostate Specific Antigen) in $59 \%$ of patients compared to chemotherapy alone (31).

All previous studies have shown low bioavailability of curcumin orally administered. Therefore further research is needed to improve the bioavailability, one of which is the liposomal curcumin formula, and the incorporation of curcumin with other substances such as piperine to increase the absorption of curcumin.

\section{CONCLUSION}

From this study we concluded that the administration of $1000 \mathrm{mg} / \mathrm{kgBW} /$ day curcumin for 30 days decreased VEGF expression in Rattus norvegicus cervical cancer xenograft model significantly with a $\mathrm{p}$ value of $0.009(<0.05)$. Further research is needed on the comparison of vascular density with tumor size as a continuation of differences in VEGF expression as a marker of the angiogenesis process.

\section{ACKNOWLEDGEMENT}

The authors are grateful to all study team at Dr. Soetomo Hospital, Surabaya.

\section{Competing of Interest}

The authors declare that have no competing interest.

\section{REFERENCES}

1. Torre LA, Bray F, Siegel RL, Ferlay J. Global Cancer Statistics , 2012. 2015;65(2):87-108.

2. McGraw SL, Ferrante JM. Update on prevention and screening of cervical cancer. World J Clin Oncol. 2014;5(4):744-52.

3. Jhawar S, Hathout L, Elshaikh MA, Beriwal S, Small W, Mahmoud O. Adjuvant Chemoradiation Therapy for Cervical Cancer and Effect of Timing and Duration on Treatment Outcome. Int J Radiat Oncol [Internet]. 2017;98(5):1132-41.

4. Teymouri M, Pirro M, Johnston TP, Sahebkar AS. Curcumin as a multifaceted compound against human papilloma virus infection and cervical cancers: A review of chemistry, cellular, molecular, and preclinical features. BioFactors. 2017;43(3):331-46.

5. Jhawar, S, Hathout L, Elsharikh M.A, Beriwal S, Small W, Mahmoud Omar 'Adjuvant Chemoradiation Therapy for Cervical Cancer and Effect of Timing and Duration on Treatment Outcome', International Journal of Radiation Oncology*Biology*Physics. Elsevier Inc., 2017. 98(5), pp. 1132-1141. doi: 10.1016/j.ijrobp.2017.03.045.

6. Tomao F, Papa A, Rossi L, Zaccarelli E, Caruso D, Zoratto $F$, et al. Angiogenesis and antiangiogenic agents in cervical cancer. Onco Targets Ther. 2014;7:2237-48.

7. Barton NW, Brady RO, Dambrosia JM, Bisceglie AM, Doppelt SH, Hill SC, et al. Tumor Angiogenesis and Metastasis - Correlation in invasive Breast Carcinoma. $\mathrm{N}$ Engl J Med. 1991;324(1):1-8.

8. Arjomandnejad M, Muhammadnejad A, Haddadi M, Sherkat-Khameneh N. HeLa Cell Line Xenograft Tumor as a Suitable Cervical Cancer Model: Growth Kinetic Characterization and Immunohistochemis-. Arch Iran Med. 2014;17(4):273-7.

9. Alon T., Hemo I., Itin A., Pe'er J., Stone J.,Keshet E. 'Vascular endothelial growth factoracts as a survival factor for newly formed reti-nal vessels and has implications for retinopa-thy of prematurity'.Nat Med; 1995.1: 1024.

10. Hoeben, A. N. N, Landuyt B, Highley M.S, Wildiers H, Oosterom A.T.V. (2004) 'Vascular endothelial growth 
factor and angiogenesis.', Pharmacological reviews, 56(4), pp. 549-580. doi: 10.1124/pr.56.4.3.549.

11. Gabrilovich D, Ishida T, Oyama T, Ran S,Kravtsov V, Nadaf S, Carbone DP,(1998) 'Vascular endothelial growth factor inhibits the develop-ment of dendritic cells and dramatically affects the differentiation of multiple hematopoietic lineages in vivo'. Blood; 92: 4150-4166.

12. Ferrara N, Henzel WJ 'Pituitary follicular cells secrete a novel heparin-binding growth factor specific for vascular endothelial cells' Biochem Biophys Res Commun; 1989.161: 851-858.

13. Prasad S, et a.l, 'Curcumin, a component of golden spice: Frombedside to bench and back' Biotechnol Adv,.2014.04.004

14. Cheng KK, Yeung CF, Ho SW, Chow SF, Chow AH, Baum L. 'Highly stabilized curcumin nanoparticles tested in an in vitro blood-brain barrier model and in Alzheimer's disease. AAPS J;2013.15:324-36.

15. Yoysungnoen-Chintana, P., Bhattarakosol, P. and Patumraj, S. 'Antitumor and antiangiogenic activities of curcumin in cervical cancer xenografts in nude mice', BioMed Research International, 2014.

16. Kuttan R, Bhanumathy $P$, Nirmala K, George MC. Potential anticancer activity of turmeric (Curcuma longa). Cancer Lett 1985.29: 197

17. Kunnumakkara AB, Bordoloi D, Harsha C, Banik K, Gupta SC, Aggarwal BB. Curcumin mediates anticancer effects by modulating multiple cell signaling pathways. Clin Sci [Internet]. 2017;131(15):1781-99.

18. Braumann, C., Guenther, N., Loeffler, L. M, \& Dubiel, W. Liver metastases after colonic carcinoma-palliative chemotherapy plus kurkumin.International Journal of Colorectal Disease,2009.24, 859-860.

19. Ghalaut VS, Sangwan L, Dahiya K, Ghalaut P, Dhankhar R, Saharan R. Effect of imatinib therapy with and without turmeric powder on nitric oxide levels in chronic myeloid leukemia. J Oncol Pharm Pract [Internet]. 2012;18(2):186-90.

20. 19. Dang YP, Yuan XY, Tian R, Li DG, Liu W. Curcumin improves the paclitaxel induced apoptosis of HPV positive human cervical cancer cells via the NF KB p53 caspase 3 pathway. Exp Ther Med. 2015;9(4):1470-6.

21. Roy $M$, Mukherjee $S$. Reversal of resistance towards cisplatin by curcumin in cervical cancer cells. Asian Pacific J Cancer Prev. 2014;15(3):1403-10.

22. Hutomo S, Susilowati $H$, Suryanto $\mathrm{YI}$, Kurniawan $\mathrm{C}$, Mikrobiologi B, Kedokteran F, et al. Perubahan morfologi sel HeLa setelah paparan ekstrak etanolik Curcuma longa kurku min menyebabkan kematian sel sebanyak Kultur sel HeLa Sel HeLa ditumbuhkan dalam medium ditambahkan medium RPMI hingga volume 10. 2016;2(1):1-5.

23. Javvadi P, Segan AT, Tuttle SW, and Koumenis C: The chemopreventive agent curcumin is a potent radiosensitizer of human cervical tumor cells via increased reactive oxygen species production and overactivation of the mito-gen-activated protein kinase pathway. Mol Pharmacol 73, 1491-1501, 2008.

24. Masters,JR. 'HeLa cells 50 years on: the good, the bad and the ugly' Cancer Nature Review,2002. vol 2.

25. Richmond A, Su Y. Mouse xenograft models vs GEM models for human cancer therapeutics. Dis Model Mech [Internet]. 2008;1(2-3):78-82.
26. Shan, B., Schaaf, C., Schmidt, A., Lucia, K., and Buchfelder, M., et al.'Curcumin suppresses HIF-1A synthesis and VEGFA release in pituitary adenomas' J. Endocrinol.2012.214, 389-398.

27. Gururaj, A. E., Belakavadi, M., Venkatesh, D. A., Marme, D., and Sali-math, B. P. 'Molecular mechanisms of antiangiogenic effect of curcumin. Biochem. Biophys'. Res. Commun. 2002. 297, 934-942.

28. Lin, Y. G., Kunnumakkara, A. B., Nair, A., Merritt, W. M., and Han, L. Y.,et al. 'Curcumin inhibits tumor growth and angiogenesis in ovar-ian carcinoma by targeting the nuclear factor-kappaB pathway' Clin.Cancer Res.2007. 13, 3423-3430.

29. Karimian MS, Katsiki N, Caraglia M, Boccellino $M$, Majeed, Sahebkar 'Vascular endothelial growth factor: an important molecular target of curcumin' Critical Reviews in Food Science and Nutrition, 2017.DOI: 10.1080/10408398.2017.1366892

30. Sharma RA, Euden SA, Platton SL, Cooke DN, Shafayat A, et al,. 'Phase I clinical trial of oral curcumin: biomarkers of systemic activity and compliance'. Clin Cancer Res.2010. 10: 6847-6854.

31. Dhillon N, Aggarwal BB, Newman RA, Wolff RA, Kunnumakkara $A B$, Abbruzzese JL, et al. Phase II trial of curcumin in patients with advanced pancreatic cancer. Clin Cancer Res. 2008;14(14):4491-9.

32. Mahammedi, H.,Planchat, E.,Pouget, M.,Durando, X.,Curé, H.,Guy, L. 'The New Combination Docetaxel, Prednisone and Curcumin in Patients with CastrationResistant Prostate Cancer: A Pilot Phase II Study' , Oncology J,2016. doi: 10.1159/000441148 